\title{
Creating Synergy: Essential Components of a Successful R25E Cancer Education Program
}

\author{
Suzanne A. Gronemeyer, PhD \\ St. Jude Children's Research Hospital, Academic Programs Office, 262 Danny Thomas Place, \\ Memphis, TN, 38105-3678, 901-595-2488, 901-595-3292, http://www.stjude.org/Gronemeyer, \\ http://www.stjude.org/poe
}

Suzanne A. Gronemeyer: suzanne.gronemeyer@stjude.org

\begin{abstract}
For an R25E cancer research program to be a resounding success for both participating students and faculty, and to maintain federal funding, many synergistic elements are necessary. Essential components of the R25E Pediatric Oncology Education (POE) Program at St. Jude Children's Research Hospital include 1) a unique focus, 2) a program director who is passionate about the program and who is enthusiastically supported by the institution, 3) committed and involved faculty mentors, 4) a current and complete program website with an online application process, 5) a large external network referring top students to the program, 6) an extensive, diverse, and highly qualified applicant pool with rigorous application requirements, 7) meticulous matching of faculty mentors with mentees, 8) adequate financial support for participants (stipend and housing), 9) an outstanding basic science and clinical research infrastructure, 10) Training in the protection of human subjects, the responsible conduct of research, and research with vertebrate animals, 11) a comprehensive lunch \& learn seminar series, 12) oral and written participant presentations of their research results, 13) ongoing internal and external program evaluation, 14) long-term tracking of participants, and 15) continuing program innovation.
\end{abstract}

\section{Keywords}

pediatric; oncology; education; cancer; biomedical; research; internship

\section{Introduction}

According to the National Cancer Institute(NCI), the Cancer Education Grants Program (CEGP) (R25E) is a flexible, curriculum-driven program aimed at developing and sustaining innovative and educational approaches that ultimately will have an impact on reducing cancer incidence, mortality, and morbidity, as well as improving the quality of life of cancer patients [1]. Of the NCI R25E programs, only short term and/or summer programs sponsored and taught by academic faculty and designed to motivate college or graduate students to pursue cancer related careers and programs to provide short-term cancer education to research scientists are eligible for renewal [2]. The need for ongoing short-term cancer education programs to attract new cancer researchers is clear [3], but establishing and maintaining an outstanding R25E summer program for pre-doctoral students is indeed a challenge. The Pediatric Oncology Education (POE) Program (5R25 CA23944) at St. Jude Children's Research Hospital, which has been in existence since 1978, is an example of a successful R25E program [4,5]. Many of the synergistic elements that make up this program are not unique, but the combination is. We describe major components of the POE program http://www.stjude.org/poe as an example of a successful R25E. 


\section{Essential Components of a Successful R25E}

\section{Unique focus}

The Pediatric Oncology Education (POE) Program at St. Jude Children's Research Hospital (St. Jude) is unique, in that it is the only NCI R25E pediatric oncology program for predoctoral students. Since cancer is the leading cause of death in childhood from medical conditions, pediatric cancer education is important for pediatricians and family medicine physicians, so that it can be diagnosed early, when it is most curable. Approximately 1 in 320 American children will develop cancer by the time they are 20 years old. Fortunately, the five-year survival rate for childhood cancer is approaching 80 percent. Some 270,000 Americans are survivors of childhood cancer [6,7]. There is a shortage in both the number and diversity of well-trained, competent pediatric oncology researchers, clinicians, and nurses in this country [8,9]. This is apparent in St. Jude recruitment of fellows, faculty, and nursing staff. St. Jude is one of the world's major centers for research and treatment of catastrophic diseases in children (primarily pediatric cancers) and is the only NCIdesignated Comprehensive Cancer Center with an exclusive focus on pediatric cancers. Thus, St. Jude is in a unique position to address these issues by stimulating interest in pediatric cancer research and patient management in talented biomedical science and health professions students.

\section{Dedicated Program Director and institutional commitment}

The Program Director (Suzanne A. Gronemeyer, PhD) joined St. Jude Children's Research Hospital in 1988 and has been Director and Principal Investigator (PI) of the Pediatric Oncology Education (POE) Program since 1997. With institutional approval, since 2000 she has devoted approximately $90 \%$ of her time to the program and related St. Jude pre-doctoral activities. Under her direction, the program has grown and transformed significantly. As an example of the institution's extraordinary commitment, when we experienced a lapse in R25E funding for the 2003 and 2004 POE programs, St. Jude provided bridge funding to continue the program at the normal level until R25E funding was reestablished.

\section{Committed and involved faculty mentors}

The POE Program Director emails St. Jude faculty in the winter to invite them to mentor a POE student in the coming summer. Every year, fifty or more faculty from across the institution volunteer as POE mentors. They consider it a privilege to participate in the program and are effusive in their support.

\section{Current, complete program website and social media presence}

Upon her appointment as POE Program Director in 1997, the PI created a program website http://www.stjude.org/poe with the program announcement and an online application https://hospital.stjude.org/apps/hospitalforms/forms/poeApplication.jsp. This resulted in a surge in the number of qualified applicants and in their geographic diversity [4]. The current website includes the Lunch \& Learn seminar schedule for the coming summer, as well as that of several prior summers (Table 1). Group photos of the POE classes of 1998 onward are also included on the website. In addition to the online application, several surveys are available on the website for the respondent to complete and deliver confidentially to the PI. They include the POE participant exit survey, the POE mentor evaluation of their student and the program, and a long-term follow-up survey for former POE participants. To facilitate program participant networking and long-term follow-up, in the summer of 2009, the PI established a significant Facebook presence for the POE Program http://www.facebook.com/people/Suzanne-Gronemeyer/1599061246. Facebook and Google 
have enabled the PI to connect with and update career path information for most program participants since inception in 1978.

\section{External referral network}

While many applicants learn about the POE program through online searches, others hear about it from prior participants, one of the many university websites listing the program, or university faculty who know about the program. St. Jude Academic Programs personnel distribute POE program information in their St. Jude exhibit booth at a number of US science conferences throughout the year, including those which attract a large number of under-represented minority (URM) pre-doctoral science students, such as ABRCMS (Annual Biomedical Research Conference for Minority Students), Leadership Alliance Symposium, Harvard's Biomedical Science Careers Symposium, and SACNAS (Society for the Advancement of Chicanos and Native Americans in Science). Academic Programs personnel also distribute program information to faculty and students during their numerous recruitment visits to universities. The PI has compiled a database of over 1700 US university faculty and cancer researchers in all 50 states, the District of Columbia, and Puerto Rico. For the 2011 program, she has emailed a brief program announcement, including requirements and information links, to all those in the database. Many recipients forward the email on to students and other faculty, and a number post the information on their departmental websites.

\section{Extensive, diverse, and highly qualified applicant pool with rigorous application requirements}

POE Program applicants must have completed at least their sophomore year of college by the time they participate in the program. They must be a US citizen or a permanent resident. Applicants must submit their college transcripts and two letters of recommendation from research mentors and/or college science professors. Applications must be submitted online no later than the February 1 deadline. To ensure authenticity, the letters of recommendation must be sent directly by the recommender to the Program Director, and the transcripts must be sealed official transcripts. Credentials must be postmarked, faxed or emailed no later than the February 1 deadline. Applicants MUST have an undergraduate GPA of at least a 3.40/4.00 in math and science (biology, chemistry, physics) AND at least a 3.40 overall. Graduate students and medical students must also meet the undergraduate GPA requirements. There are no exceptions to the requirements. The POE 2009 class average undergraduate GPA was 3.803, and for the POE 2010 class was 3.825. POE participants new to the program must commit to working at St. Jude for 11 weeks, while 10 weeks is required for returning participants, and 9 weeks for medical students. Many new participants already have research experience, which usually has a positive impact on their performance in our program. Annually, there are 400-500 applicants for about 50 positions. Female applicants (and program participants) outnumber males approximately 2 to 1 . Each year, 15$20 \%$ of applicants (and program participants) identify as members of groups underrepresented in the biomedical sciences (URM). In the 2005-2010 period, there were applicants from over 200 schools in over 40 states (including Puerto Rico and the District of Columbia) each year. In the same period, participants were from more than 40 schools in over 20 states annually.

\section{Meticulous matching of faculty mentors with mentees}

The PI receives program applications by email and enters them in a FileMaker Pro database. She processes incoming applicant credentials and pre-screens all applications to ensure that applicants meet all program requirements. By searching the applicant database, the Program Director helps each faculty mentor individually identify a number of potential matches from the pool of eligible applicants. Basic science mentors then examine potential candidate files 
to select a specific student. Selection criteria include 1) the student's coursework, laboratory experience and any research experience relevant to the mentor's area of research; 2) the areas in which the student has expressed interest; 3 ) the student's letters of recommendation from their research mentors and college science professors; 4) email and phone discussion with the student to assess their level of interest and knowledge; 5) the student's career goals, with an emphasis on placing students with a potential career interest in cancer research and/ or cancer patient care; 6) conversations with the student's references; and 7) discussions with the POE Program Director. Clinical mentors use similar criteria to select a student from the medical student applicant pool, giving preference to applicants interested in a career in pediatric oncology or a related area in which St. Jude has particular expertise.

Each year, several members of prior POE classes return for an additional POE appointment. POE students (POEs) who are invited to return did well in their first POE appointment and express a strong interest in a second POE experience. They often return to the same group in which they worked the prior summer, but occasionally elect to gain experience in a different research area. If returning as a medical student, they work in a clinical area. Returning POEs are a wonderful resource for both the new POEs and the PI. They relish their status as role models, peer mentors, and are de facto group leaders. Their eagerness to return to St. Jude also serves as a testament to what they feel they gain from the program and institutional environment. The 51 members of the POE 2010 class included 13 medical students, 33 undergraduates (including May 2010 graduates), three PharmD students, and two graduate/ post-baccalaureate students. Two were sophomores with prior research experience; all others were further along in their academic careers. Fourteen 2010 participants were prior POEs returning for an additional POE rotation.

\section{Adequate financial support for program participants}

If they complete their full appointment as stipulated in their appointment letter, the POE participant receives a stipend totaling $\$ 4,000$. They receive a check for the first $\$ 1,500$ of their stipend during POE orientation with the PI on their first day. They receive a second $\$ 1,500$ check mid-program, and a final check for $\$ 1,000$ on their last day during their exit interview with the PI. Approximately $80 \%$ of POE program participants are from outside the Memphis area. To enable applicants to compete equally for positions, housing is provided free of charge to non-local participants. As a private research institution, we do not have access to student dormitory housing, such as might be available if we were a university. Non-local participants are housed in furnished group apartments within walking distance of the St. Jude campus. The apartments are furnished with basic linens, house wares, furniture, and appliances. By having participants share the apartments (typically four in a 2-bedroom, 2-bath apartment), we are able to provide housing for the summer at a cost of approximately $\$ 1,100$ per student. Group housing also fosters networking, which students report to be a major positive program impact. Free housing is often a deciding factor for minority participants and those coming from great distances. We do not provide transportation funding, but the PI is often able to obtain per diem support from the FASEB MARC Summer Research Opportunity Program [10] for undergraduate URM POEs who express an interest in pursuing a $\mathrm{PhD}$.

\section{Outstanding basic science and clinical research infrastructure}

St. Jude Children's Research Hospital is an internationally recognized research and treatment center dedicated to finding cures for catastrophic childhood diseases. St. Jude has particular strengths in the leukemias, lymphomas, solid tumors, HIV/AIDS, immunodeficiencies, genetic diseases and hematologic disorders such as sickle cell disease. St. Jude is an NCI-designated Comprehensive Cancer Center. Founded by the late entertainer Danny Thomas, St. Jude opened its doors February 4, 1962. St. Jude now has 
210 faculty-level basic research and clinical research faculty, as well as approximately 300 postdoctoral research associates, 150 clinical residents and fellows, and 70 graduate research scholars. Only the very best scientists are recruited to be St. Jude faculty members. This group currently includes 1 Nobel laureate, 2 members of the National Academy of Sciences, 3 Howard Hughes investigators, 6 members of the Institute of Medicine, and 4 Pew Scholars. St. Jude is organized into a departmental structure similar to that of a university or medical school; however, most faculty members conduct research within a programmatic structure in which investigators with common goals and interests collaborate across departmental boundaries. Endowed Chairs head the 17 academic departments at St. Jude: Biochemistry, Biostatistics, Chemical Biology \& Therapeutics, Developmental Neurobiology, Epidemiology \& Cancer Control, Genetics, Hematology, Immunology, Infectious Diseases, Oncology, Pathology, Pharmaceutical Sciences, Psychology, Radiological Sciences, Structural Biology, Surgery, and Tumor Cell Biology.

On January 25, 2010, St. Jude Children's Research Hospital and Washington University School of Medicine in St. Louis announced an unprecedented effort to identify the genetic changes that give rise to some of the world's deadliest childhood cancers. The team has joined forces to sequence the genomes of more than 600 childhood cancer patients who have contributed tumor samples for this historic effort. The St. Jude Children's Research Hospital - Washington University Pediatric Cancer Genome Project is the largest investment to date — estimated to cost $\$ 65$ million over three years-aimed at understanding the genetic origins of childhood cancers. Scientists involved in the project are sequencing the entire genomes of both normal and cancer cells from each patient, and comparing differences in the DNA to identify genetic mistakes that lead to cancer.

The success of future biomedical research depends on the availability of well-trained young investigators. St. Jude is dedicated to nurturing and supporting these clinicians and scientists. The education and training programs at St. Jude reflect the institution's commitment to excellence. The relatively small size of St. Jude allows clinical and basic science investigators to work closely together to efficiently translate scientific discoveries from the bench to the clinic to improve therapies for children with catastrophic diseases. Perhaps the greatest strength of the education program, and one that has been present since the earliest years, is the day to day interaction between research oriented physician-scientists and laboratory investigators, which fosters an awareness of cancer as a problem that crosses many lines of inquiry. With excellent financial support, superb infrastructure, and first-rate faculty, St. Jude offers a truly unique training opportunity.

\section{Training in the protection of human subjects, the responsible conduct of research, and research with vertebrate animals}

St. Jude requires that all clinical research professionals or persons having contact with St. Jude research subjects or the subjects protected health information must complete the online web-based Collaborative Institutional Training Initiative (CITI) human subjects research training course. All clinical protocols and grants involving human subjects or identifiable human materials are reviewed and approved by the Institutional Review Board (IRB) prior to their initiation and are subject to continuing review. Any human subjects or identifiable human materials research performed by POE program participants is covered by their mentor's IRB-approved protocol. All POEs are required to complete CITI training on the protection of human research subjects prior to starting their research at St. Jude, whether or not they will be working with human subjects or identifiable human materials. The Director of the Office of Human Subjects Protections speaks on "Ethical Issues in Pediatric Clinical Research" for the POE Lunch \& Learn Series (Table 1). Additionally, all POEs are required to take the CITI online course on the Responsible Conduct of Research prior to beginning their research at St. Jude. The Chair of Structural Biology speaks on "Responsible Conduct 
of Research" for the POE Lunch \& Learn Series (Table 1). All research projects and grants using animals are covered by a protocol that has been reviewed and approved by the Institutional Animal Care and Use Committee (IACUC) prior to project inception. Protocols and grants are reviewed annually. The animal care program at St. Jude is fully accredited by the Association for the Assessment and Accreditation of Laboratory Animal Care, International (AAALAC). All POEs who will be working with vertebrate animals are required to complete St. Jude Animal Resources Center training before they can work with vertebrate animals.

\section{Comprehensive Lunch \& Learn seminar series}

The 50-session POE Lunch \& Learn seminar series, which is designed specifically for the POE students and which they are required to attend, begins the first week of June and runs through late August. The schedule for the upcoming and recent series are posted on the POE website http://www.stjude.org/poe. The speakers in June and July (Table 1) are leaders in their field, who present state-of-the-art information. Speakers relay the excitement and live action in our "bench to bedside and back" environment. Panelists from St. Jude discuss their career paths during two Lunch \& Learns. Deans from the University of Tennessee Health Science Center (UTHSC) in Memphis present two Lunch \& Learns on medical and professional schools, including interviewing tips. For the remainder of the Lunch \& Learn series, the speakers are the students themselves, who report on their POE research projects to their peers, faculty, and lab colleagues. Having lunch together daily just prior to the talks enables participants to network. This networking opportunity is especially valuable for undergraduates, who get to know medical and graduate students from many schools. Funds for food for the Lunch \& Learns are a line item in our R25E budget. Lunches are served by the St. Jude in-house catering service or occasionally an outside catering service.

In mid-July, the POE group visits the University of Tennessee Health Science Center for a tour of the facility and to meet with deans and students in their graduate school and colleges of medicine, pharmacy, and nursing.

POE medical students see patients with their mentor. Many of the other students meet clinicians after their Lunch \& Learn presentations and arrange informally to accompany them on patient rounds. Many POEs volunteer for in-patient volunteer opportunities such as "Happy Cart" and at the St. Jude on-campus patient domiciliary facility, the Memphis Grizzlies House. In these activities, students get to know patients and their families. Most POEs take advantage of the opportunity to spend a half-day with an adult oncologist seeing patients in the University of Tennessee Cancer Institute clinics. Most POEs also elect to spend a day observing surgeries in the St. Jude operating room.

POEs attend the weekly Tumor Board conference. POE medical students also attend the weekly Leukemia/Lymphoma, Hematology and Bone Marrow Transplantation and Cellular Therapy Conference. In addition, St. Jude has a plethora of research seminars, clinical conferences, and lectures by internationally known speakers, which students are encouraged to attend. Returning students may elect to attend more of the clinical and research conferences, in lieu of attending all the Lunch \& Learn sessions. However, all POEs attend the POE research project report sessions, which comprise the Lunch \& Learns beginning in late July and running throughout August.

\section{Oral and written participant presentations of research results}

Since 2001, POEs have been required to give a PowerPoint presentation on their research project as part of the POE Lunch \& Learn series. For POE project reports days, three students give 12-15 minute talks, each followed by five minutes of questions. Their 
mentors, research group, and others working with them in their departments attend and have their photo taken with their student after the student's presentation.

Since 2000, all participants have been required to submit a report on their research project written in the style of a journal in which their mentor publishes. Often, this paper is the starting point for a co-authored St. Jude publication for the student. As of December 2010, 196 (27.6\%) of the 721 individuals in POE 1997-2009 classes are co-authors on 216 peerreviewed St. Jude publications in leading journals, including Blood, Cancer, Cancer Research, the Journal of Clinical Oncology, Leukemia, Science, Nature, and the Proceedings of the National Academy of Sciences. Several former POEs have multiple St. Jude publications. Among POE 2000 participants, 37.9\% are coauthors on St. Jude publications, a marked increase from the $19.9 \%$ average for the three years (1997-1999) prior to instituting the journal-style paper requirement in 2000. Beginning in 2005, each POE manuscript is reviewed by two St. Jude postdoctoral research associates and assigned a number grade, using the NIH scoring system. Each year, 20-25 postdoctoral research associates volunteer to be POE manuscript reviewers. They consider it an opportunity to gain needed professional experience as a reviewer. In response to student suggestions, the three best POE clinical science and the three best basic science manuscript authors are recognized with modest cash awards. This provides added incentive and helps foster friendly competition to write excellent papers. With times from research experience to publication typically $2-5$ years, both the number of publications for recent students and the percentage with St. Jude publications continue to rise. Publication rates are on track to approach 50\% for the 2005 class and following years.

\section{Ongoing internal and external program evaluation}

All POE program participants take a test to evaluate their general knowledge of pediatric oncology and biomedical research ethics at the beginning of their appointment. On their last day, all retake the same test. POE 2005-2010 student scores improved from an average of $54.4 \%$ incoming to $83.8 \%$ outgoing.

At the conclusion of the student's appointment, the mentor completes an online evaluation https://hospital.stjude.org/apps/hospitalforms/forms/poeMentorEval.jsp of their student and the POE program. The Program Director receives the evaluation as an email and responds to the mentor by email. Mentor compliance with the request for student evaluation is close to $100 \%$. Comments about the POE students are positive in all but a few cases. Comments on the program are uniformly positive. Suggestions for program improvements are seriously considered and implemented when feasible.

At the conclusion of their appointment, all participants complete an online evaluation https://hospital.stjude.org/apps/hospitalforms/forms/poeExitSurvey.jsp of the program and their mentor. The Program Director receives the exit survey as an email and responds to the student by email and during their exit interview with her. Results are used to help identify areas for improvement in the program and to identify any previously unreported problems the student might have encountered. When appropriate and feasible, student suggestions are implemented. Should a student evaluate their mentor negatively $(0 \%$ incidence in recent years), the student's comments are considered carefully in deciding whether to place a future POE with that mentor. Usually, students and mentors report any difficulties early on to the Program Director, enabling her to negotiate solutions.

Funds are included as a line item in the POE R25E budget for the program to be reviewed by consultants during the summer while the program is in progress. The consultants are experienced NCI R25E investigators who work in a cancer education and training setting. The consultant spends two days at St. Jude reviewing the POE program and meeting with 
program participants, mentors, the Program Director (PI), and St. Jude leadership. The consultant attends Lunch \& Learn with the students and hears students report on their POE program research. Prior to the consultant's visit, the PI emails the consultant relevant materials, such as the most recent renewal application, summary statement, and progress reports. The consultant submits verbal and written evaluations of the program and any recommendations for improvements to the PI. The results help identify strengths and weaknesses in the program and foster continuing improvement. Letters of support from recent consultants are included in competing and continuing renewal requests to the National Cancer Institute.

\section{Long-term tracking of program participants}

As noted earlier, in the summer of 2009, the PI established a significant Facebook presence for the POE Program http://www.facebook.com/people/Suzanne-Gronemeyer/1599061246 to facilitate program participant networking and long-term follow-up. As of the 2009 program, 893 different students had participated in the St. Jude program, 143 (16.0\%) for more than one summer. With the aid of Facebook and Google, in 2009-2010 the PI was able to update information on $879(98.4 \%)$ of the 893 participants since inception (1978-2009). Fourteen of the 893 are lost to follow-up, and seven are deceased. Of the $696(77.9 \%)$ participants who had completed their degree work, $596(85.6 \%)$ held a doctorate, including $146(76.8 \%)$ of the 190 URM participants in the cohort. Of the 893 participants since 1978 (many of whom were still in training), 176 (19.7\%) had a cancer career goal, $88(9.9 \%)$ were in cancer-committed careers, and $58(6.5 \%)$ were already involved in cancer research. Those who are in cancer-committed careers include 14 pediatric hematologist-oncologists, 14 adult hematologist-oncologists, 9 radiation oncologists, 9 surgical oncologists, 8 medical physicists, 2 nuclear/oncologic pharmacists, and 14 oncology nurses, physician assistants, or clinical research associates. Twenty former POEs hold an $\mathrm{MD} / \mathrm{PhD}$ or are currently in an $\mathrm{MD} / \mathrm{PhD}$ program, many in cancer research areas. Thirty-seven hold $\mathrm{PhDs}$ or are in $\mathrm{PhD}$ programs, most in cancer research areas. Eighty-one of those far enough along in their careers (POE 2001 and earlier) hold academic appointments.

\section{Continuing program innovation}

Just as in the business world, constant innovation is a sine qua non for an R25E program to remain competitive and prove worthy of renewal funding. The St. Jude program has been successful to date in part by embracing new technological developments, such as establishing a web presence in 1997 [4], utilizing search engines for follow-up in 2003-2004 [5], and adopting Facebook to find a great many "lost sheep" in 2009.

\section{Conclusion}

Each R25E summer internship program has its strengths and weaknesses. While many of the synergistic elements that make up the St. Jude Children's Research Hospital POE program are not unique, their combination is. We have described the major components of the POE program http://www.stjude.org/poe as an example of a successful long-running R25E summer internship. We look forward to benefitting from detailed descriptions of other such programs in future issues of this journal.

\section{Acknowledgments}

The St. Jude Children's Research Hospital Pediatric Oncology Education (POE) Program is supported by grants from the National Cancer Institute (5R25CA23944 and P30CA-21765) and the American Heart Association, and by funding from the American Lebanese Syrian Associated Charities (ALSAC). 


\section{References}

1. Training, Career Development \& Education Funding. Cancer Education Grants Program (R25E). [Accessed 10 December 2010.]. http://www.cancer.gov/researchandfunding/training/r25e

2. Program Announcement (PA) Number: PAR-08-120. Title: Cancer Education Grants Program (R25). [Accessed 10 December 2010.]. http://grants.nih.gov/grants/guide/pa-files/PAR-08-120.html

3. Michalek AM, Johnson CR. Cancer research training for high school and college students at a comprehensive cancer center. J Cancer Educ. 2004 Winter;19(4):209-11. [PubMed: 15725637]

4. Gronemeyer SA. Effective use of the Web to expand a summer predoctoral program: The St. Jude Experience. J Cancer Educ. 2000; 15:200-204. [PubMed: 11199235]

5. Gronemeyer SA. The impact of predoctoral pediatric oncology education. J Cancer Educ. 2005; 20:16-22. [PubMed: 15876177]

6. American Cancer Society. Cancer Facts and Figures. Atlanta, GA: American Cancer Society; 2007.

7. Ries, LAG.; Melbert, D.; Krapcho, M., et al. SEER Cancer Statistics Review, 1975-2004. Bethesda, MD: National Cancer Institute;

8. Althouse LA, Stockman JA 3rd. Pediatric workforce: a look at pediatric hematology-oncology data from the American Board of Pediatrics. J Pediatr. 2006 Apr; 148(4):436-437. [PubMed: 16647400]

9. Friedman AL. American Academy of Pediatrics Committee on Pediatric Workforce. Enhancing the diversity of the pediatrician workforce. Pediatrics. 2007 Apr; 119(4):833-7. [PubMed: 17403859]

10. FASEB MARC Summer Research Opportunity Program. [Accessed 12 December 2010]. http://www.faseb.org/Marc/MARC-and-Professional-Development/Travel-Awards/-SummerResearch-Opportunity-Program.aspx 
Table 1

Faculty presentations for the St. Jude POE 2010 Lunch \& Learn Series

\begin{tabular}{|c|c|c|}
\hline Date & Speaker & Topic \\
\hline Tue $6 / 1$ & Raul Ribeiro, MD & Pediatric Leukemia \\
\hline Wed $6 / 2$ & Mihaela Onciu, MD & The Laboratory Workup of Pediatric Leukemias \\
\hline Thu $6 / 3$ & Gopal Murti, PhD & St. Jude: Past, Present, and Future \\
\hline Fri $6 / 4$ & Kathy Price, RN, MBA & Ethical Issues in Pediatric Clinical Research \\
\hline Mon 6/7 & Mary Relling, PharmD & Pharmacogenetics \\
\hline Tue $6 / 8$ & Stephen White, DPhil & Responsible Conduct of Research \\
\hline Wed 6/9 & $\begin{array}{l}\text { Medical, Nursing, Pharmacy, Graduate School } \\
\text { Deans, UTHSC }\end{array}$ & Medical School and Graduate School: Admission and Survival \\
\hline Thu 6/10 & Furhan Yunus, MD, FACP & Adult Oncology \\
\hline Fri $6 / 11$ & Roland Kaddoum, MD & Anesthesiology in Pediatric Oncology \\
\hline Mon 6/14 & Alberto Pappo, MD & Pediatric Body Tumors \\
\hline Tue $6 / 15$ & Beth McCarville, MD & Diagnostic Imaging of Pediatric Tumors \\
\hline Wed $6 / 16$ & Scott Howard, MD & Pediatric Lymphomas \\
\hline Thu 6/17 & Andrew Davidoff, MD & Surgery and Pediatric Body Tumors \\
\hline Fri $6 / 18$ & Frederick Boop, MD & Pediatric Brain and Spine (CNS) Tumors \\
\hline Mon 6/21 & Jesse Jenkins, MD & The Role of the Surgical Pathologist in Pediatric Cancer Diagnosis \\
\hline Tue $6 / 22$ & William Greene, PharmD & Chemotherapy in Pediatric Oncology \\
\hline Wed $6 / 23$ & Atmaram S Pai Panandiker, MD & Radiation Therapy in Pediatric Oncology \\
\hline Thu $6 / 24$ & Mari Dallas, MD & Hematopoietic Stem Cell Transplantation in Pediatric Patients \\
\hline Fri $6 / 25$ & Melissa Hudson, MD & Long-term Effects of Pediatric Oncotherapy \\
\hline Mon 6/28 & Gerard Zambetti, PhD & The p53 Tumor Suppressor Signaling Pathway and Cancer \\
\hline Tues $6 / 29$ & Charles Sherr, MD, PhD & Tumor Suppressors Regulating Cellular Self-Renewal \\
\hline Wed $6 / 30$ & Michael Dyer, PhD & Retinoblastoma: Bridging Developmental Neurobiology and Cancer Genetics \\
\hline Thu $7 / 1$ & Jane Hankins, MD, MS & Sickle Cell Disease \\
\hline Fri $7 / 2$ & St. Jude Panelists & St Jude Career Paths 1 \\
\hline Tues $7 / 6$ & Hana Hakim, MD & Infectious Diseases and Pediatric Oncology \\
\hline Wed $7 / 7$ & $\begin{array}{l}\text { Dean Nelson Strother and Gerald Presbury, MD, } \\
\text { UTHSC }\end{array}$ & What You Always Wanted to Know about Interviewing for Medical School \\
\hline Thu $7 / 8$ & Judith Wilimas, MD & Pediatric Hematology/Oncology Worldwide: the St. Jude Contribution \\
\hline Fri $7 / 9$ & Aditya Gaur, MD & Pediatric HIV/AIDS \\
\hline Mon $7 / 12$ & Russell Ware, MD, PhD & Hemolytic Anemia \\
\hline Tues $7 / 13$ & Richard Gilbertson, $\mathrm{MD}, \mathrm{PhD}$ & Where Do Brain Tumors Come From? \\
\hline Wed $7 / 14$ & University of Tennessee Health Science Center & Campus tour \& lunch with students and deans \\
\hline Thu 7/15 & Ulrike Reiss, MD & Bone Marrow Failure Syndromes \\
\hline Fri $7 / 16$ & Justin Baker, MD & Pediatric Palliative and End of Life Care \\
\hline Mon 7/19 & Richard Webby, PhD & Emergence and Control of Pandemic Influenza \\
\hline Tue $7 / 20$ & St. Jude Panelists & St Jude Career Paths 2 \\
\hline
\end{tabular}

